\title{
Ophthalmological symptoms in a patient with reversible cerebral vasoconstriction syndrome: a case report
}

\author{
Rijo Hayashi ${ }^{*}$ D , Shimmin Hayashi ${ }^{1,2}$ and Shigeki Machida ${ }^{1}$
}

\begin{abstract}
Background: Reversible cerebral vasoconstriction syndrome is characterized by severe headache with reversible segmental constriction of the cerebral arteries. We present details on a patient with reversible cerebral vasoconstriction syndrome who initially visited an ophthalmologist because of visual symptoms.

Case presentation: A 34-year-old Japanese woman complained of sustained headache and insomnia starting 2 days after her first childbirth. In addition to the severe headache, a visual field defect was also observed 10 days later. Best corrected visual acuity at the initial visit was 20/20 and 20/25 for the right and left eye, respectively. Exudative retinal detachment was noted surrounding both optic heads. Visual field testing revealed left homonymous hemianopsia, while magnetic resonance imaging demonstrated the presence of edema and infarction of the bilateral basal nuclei and right occipital lobe. The homonymous hemianopsia and exudative retinal detachment recovered immediately after treatment with a free-radical scavenger and anticoagulant. There has been no recurrence of symptoms during the 4 years of follow-up.
\end{abstract}

Conclusions: We report a case of reversible cerebral vasoconstriction syndrome with ophthalmological symptoms that were reversible, including serous retinal detachment and homonymous hemianopsia.

Keywords: Reversible cerebral vasoconstriction syndrome, Ophthalmological symptoms, Thunderclap headache, Postpartum, Homonymous hemianopsia, Exudative retinal detachment

\section{Background}

The incidence of stroke in the peripartum and postpartum periods has increased in recent years and might correspond to the observed increase in pregnancy-induced hypertension $[1,2]$. There are several conditions associated with hypertension, including posterior reversible encephalopathy, reversible cerebral vasoconstriction syndrome, and cerebral venous sinus thrombosis, along with an increased risk of stroke and vascular dementia [1].

\footnotetext{
*Correspondence: Ihayashi@dokkyomed.ac.jp

${ }^{1}$ Department of Ophthalmology, Saitama Medical Center, Dokkyo

Medical University, 2-1-50 Minamikoshigaya, Koshigaya, Saitama

343-8555, Japan

Full list of author information is available at the end of the article
}

Reversible cerebral vasoconstriction syndrome (RCVS) is characterized by reversible constriction of cerebral arteries associated with severe headache [3, 4], which is referred to as thunderclap headache [5]. There are various precipitating factors, with the most common being postpartum [6] and exposure to vasoactive substances $[4,7]$. Patients with RCVS usually visit emergency rooms because of the severe headache. However, postpartum patients with RCVS usually visit obstetricians. Visual deficits have only been reported in $29 \%$ of RCVS patients [8], and ophthalmological findings have yet to be reported in detail. In this report, we present ophthalmological findings for a patient with RCVS who visited our clinic because of visual field defects. 


\section{Case presentation}

A 34-year-old Japanese woman suffered from headache and insomnia starting 2 days after her first childbirth. During her pregnancy, she did not experience any complications, including pregnancy-induced hypertension. However, postpartum hypertension was noted (160$170 \mathrm{mmHg} / 90-100 \mathrm{mmHg}$ ). She visited our clinic complaining of a visual field defect that had appeared 8 days after her headache onset.

Corrected visual acuities for the right and left eye were $20 / 20$ and $20 / 25$, respectively. Intraocular pressure in both eyes was $15 \mathrm{mmHg}$. The anterior segments and lenses appeared normal. Multiple yellowish dots in the deep retina were noted around the optic nerve head in both eyes (indicated by the arrows in Fig. 1), and resembled Elschnig's spots and ischemic choroidal infarcts [9]. Optical coherence tomography (OCT) demonstrated exudative retinal detachments around the optic nerve head in both eyes (Fig. 2). Visual field testing conducted by standard automated perimetry showed left homonymous hemianopsia (Fig. 3a).

We referred the patient to a neurologist for neurological examinations regarding the headache and left homonymous hemianopsia. Results from serum biochemistry tests and a cerebrospinal fluid examination were normal. Magnetic resonance imaging (MRI) revealed edema in the basal ganglions and right occipital lobe (Fig. 3b).

At day 2 after starting treatments with an infusion of a free-radical scavenger (edaravone, $60 \mathrm{mg}$ per day) and anticoagulant (heparin sodium, 10,000 U per day), the

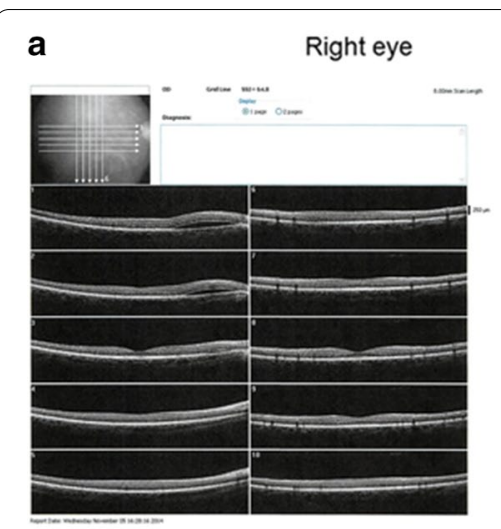

b

Left eye
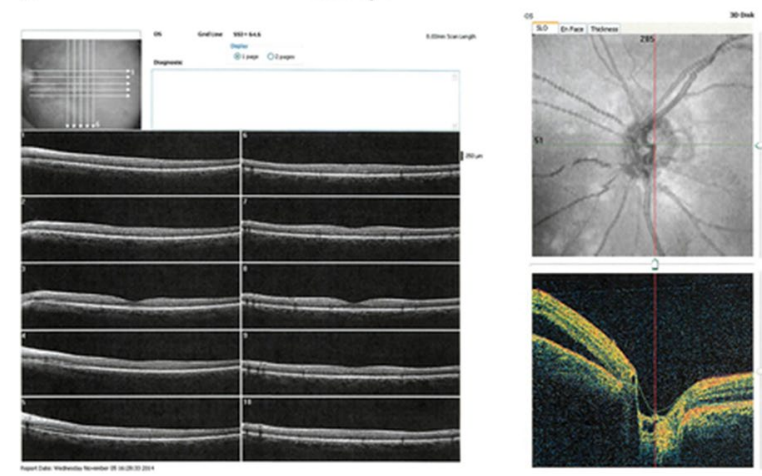

Fig. 2 Optical coherence tomography examination near the optic head at the first visit. Exudative retinal detachments were associated with both optic heads and corresponded to the peripapillary exudative edema. a right eye, $\mathbf{b}$ left eye

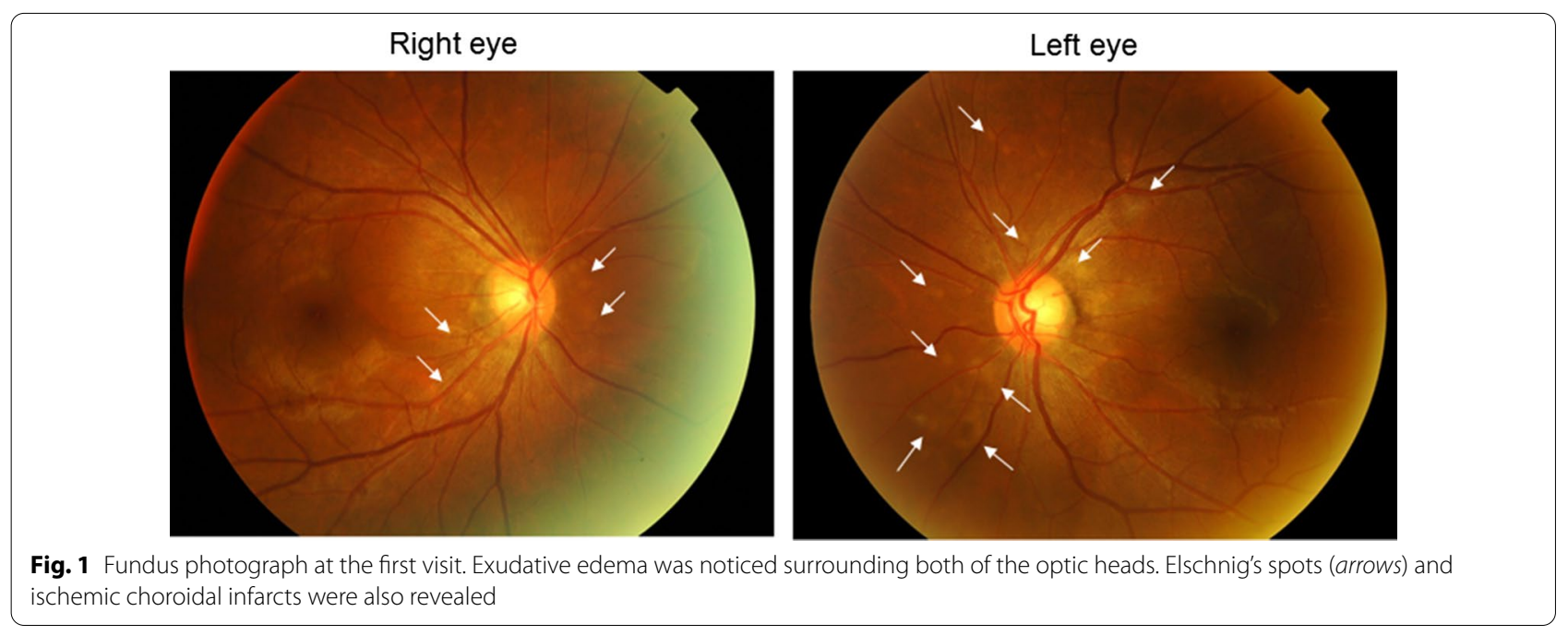




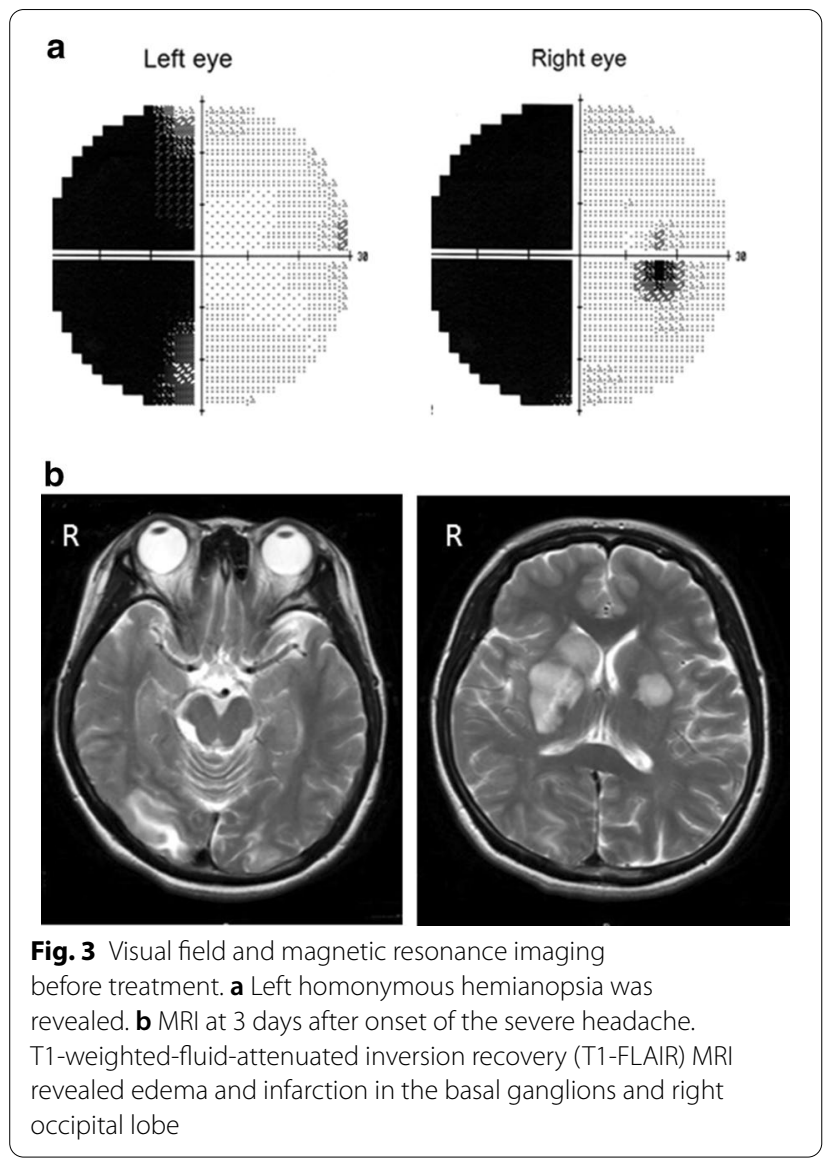

left homonymous hemianopsia disappeared (Fig. 4a) and MRI showed subsidence of the brain edema (Fig. 4b). The treatment was continued for 3 days, and the patient's symptoms improved. After improvement of the visual symptoms, cerebral angiography appeared normal (Fig. 5), and the yellowish dots in the deep retina (Fig. 6a) and exudative detachments around the optic nerve heads were no longer observed (Fig. 6b). There has been no recurrence of symptoms during the 4 years of follow-up.

The patient gave consent for her clinical details and clinical images to be published.

\section{Discussion}

RCVS is an acute and self-limiting disease commonly accompanied by acute, severe headache. The most significant contributor to RCVS is being postpartum [10-12], with hypertension also reported to be a contributing factor [13]. The present patient suffered from both hypertension and severe headache at 2 days after her first childbirth. However, there was improvement in the headache and visual symptoms within 2 weeks. The clinical course of this patient was consistent with that for RCVS.

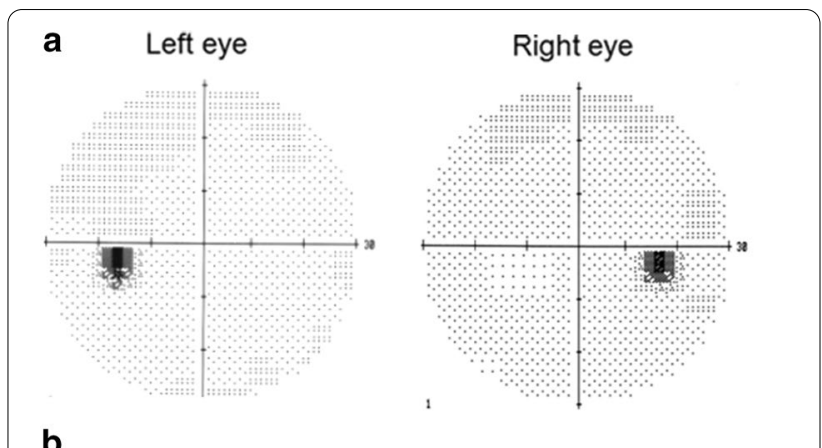

b
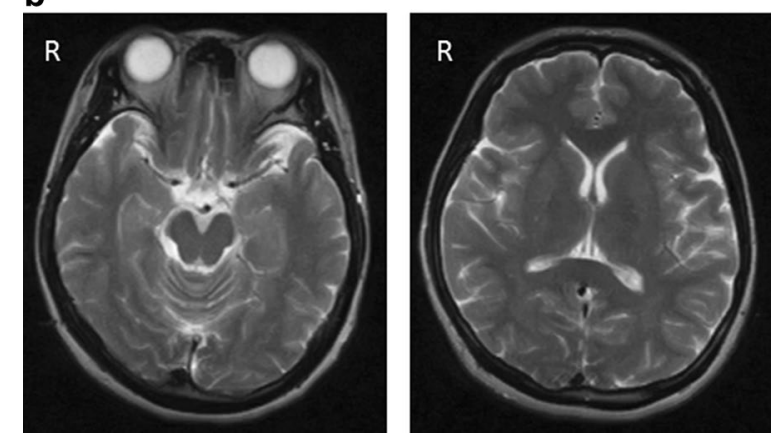

Fig. 4 Visual field and magnetic resonance imaging after treatment. a Left homonymous hemianopsia improved at 2 days after infusion of a free-radical scavenger and anticoagulant. $\mathbf{b} \mathrm{MRI}$ at 1 month after treatment. The lesions in the basal ganglions and occipital lobe were no longer visible in the follow-up MRI

On cerebral angiography, RCVS can present as segmental narrowing and dilation of one or more arteries [4]. However, vasoconstriction in cerebral angiography is not essential in the diagnosis of RCVS, as the sensitivity has been reported to be only about 70\% [14]. The normal angiography observed in RCVS patients may be due to the timing, as vasoconstriction may not be revealed during the 2 weeks after the initial clinical onset [15]. The normal cerebral angiography observed in our patient occurred after the improvement of symptoms, so the vasoconstriction could have possibly been in remission. The presence of hemorrhage or aneurysm should be ruled out for a diagnosis of RCVS $[8,16]$. Neither hemorrhage nor aneurysm was found in our patient, who was correctly diagnosed with RCVS.

Because of visual deficits, the patient presented to our clinic instead of visiting either the emergency room or her obstetrician. Blurred vision has been previously reported to be one of the clinical manifestations of RCVS that is due to brain lesions $[8,10,12,13,17]$. Although homonymous hemianopsia was previously reported in a case examined using a confrontation visual field test [17], detailed ocular findings have not been reported in other prior RCVS cases. However, 
a

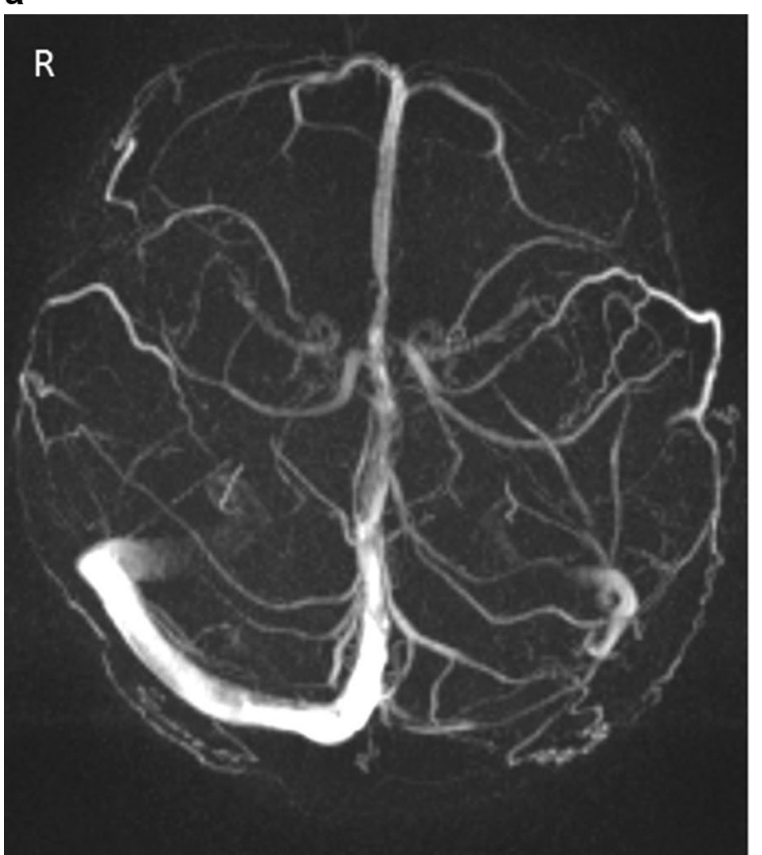

b

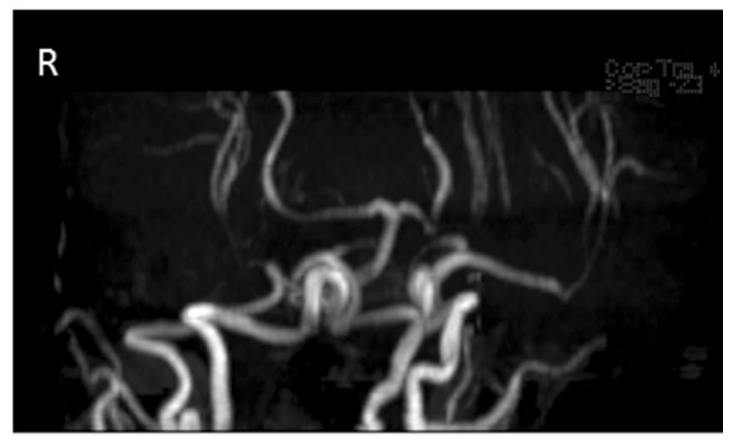

Fig. 5 Angiography performed after improvement of homonymous hemianopsia. Normal angiography was observed in the patient following improvement of the homonymous hemianopsia. a Magnetic resonance venography. $\mathbf{b}$ Magnetic resonance angiography

deterioration of visual acuity and visual field defects have been reported in patients with postpartum posterior reversible encephalopathy syndrome (PRES) [18-20], which shares several common clinical and radiologic features with RCVS [21]. Although PRES frequently exhibits a symmetric distribution of changes in the parietooccipital lobes with a moderate headache, these findings were not consistent with the results found in our patient. Vasoconstrictive involvement of the parietooccipital lobes might be a mechanism for severe visual deficits [22], and is one possible explanation for the homonymous hemianopsia in our patient.

Exudative retinal detachments have also been reported in PRES patients with hypertension [23] and in pregnancy [24]. Previous studies have reported finding constriction of choroidal arterioles in the acute ischemic phase of hypertension [25], followed by patchy filling of choroidal capillaries [26] and dysfunction of the retinal pigment epithelium [25], which induced exudative retinal detachment. The exudative retinal detachment found in our patient may also have been due to the same mechanism, with the presence of the Elschnig's spots supporting the constriction of choroidal arterioles.

Excellent clinical outcome has been reported in $80 \%$ of patients [6], with fatalities reported in less than $1 \%$ of RCVS cases $[8,13,16]$. However, there has been a higher nonbenign outcome rate reported in postpartum RCVS, with death in $20 \%$ and residual deficits in $30 \%$ of the cases [27]. Thus, close observation of patients with postpartum RCVS is necessary. In addition, any abnormal ocular findings on diagnostic examinations should be considered potential visual defects associated with the initial symptoms of RCVS.

\section{Conclusions}

In this study, we reported on a patient with a visual defect that was an initial symptom of RCVS. This is the first report to present ophthalmological findings for RCVS. Although RCVS is known to have a good prognosis, sometimes stroke or neurological sequelae can complicate the condition, and thus, close observation of these patients is necessary. 
a

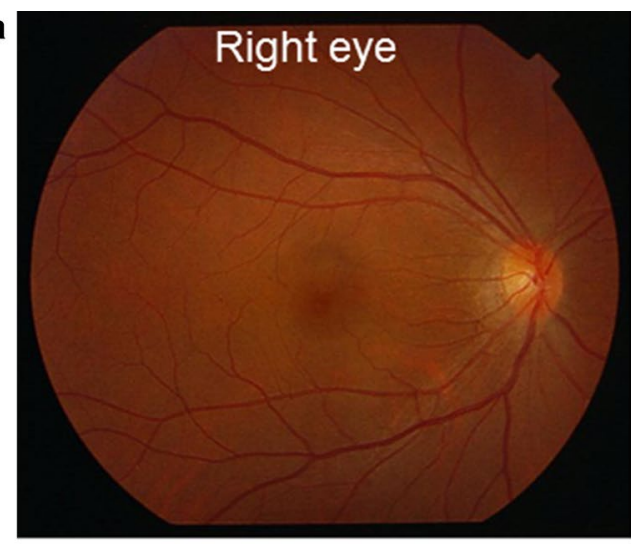

b

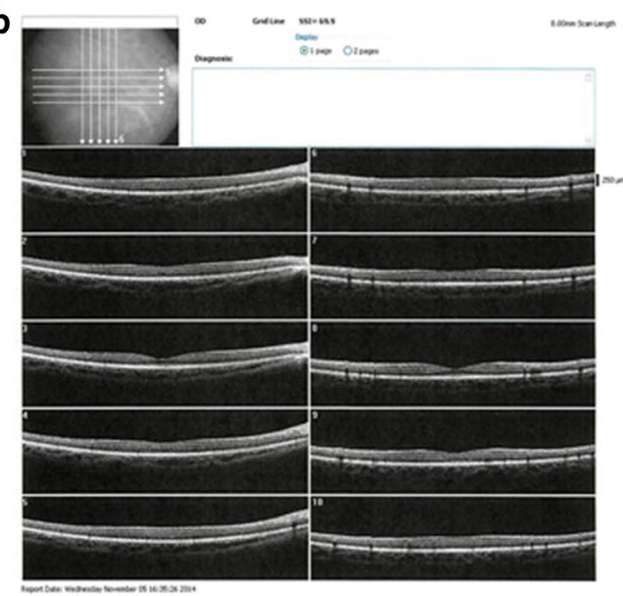

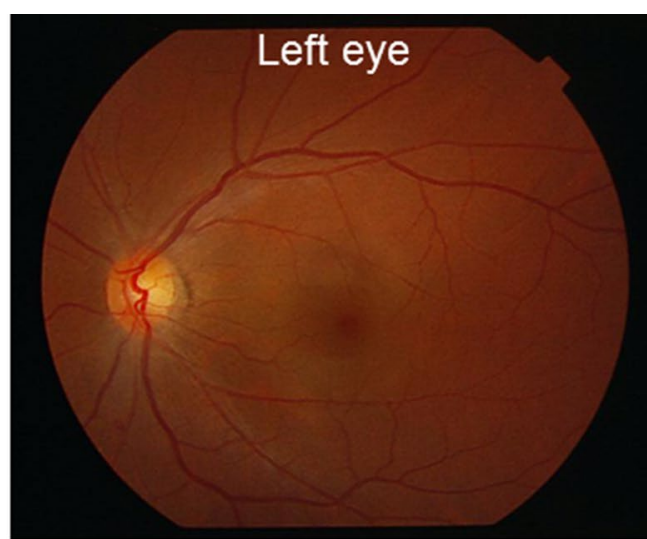

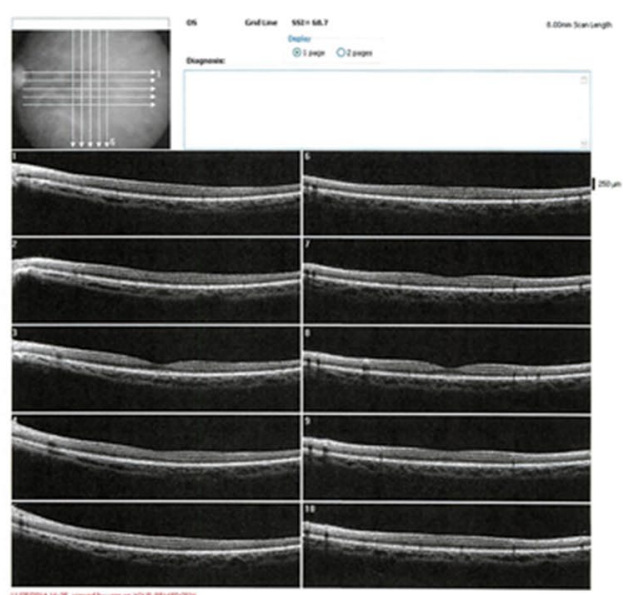

Fig. 6 Fundus photograph and OCT at 1 month after treatment. a Exudative retinal detachments and exudative edema surrounding the optic heads were no longer visible in the images. $\mathbf{b}$ Exudative retinal detachment and edema were no longer visible in the images

\section{Abbreviations}

RCVS: Reversible cerebral vasoconstriction syndrome; OCT: Optical coherence tomography; MRI: Magnetic resonance imaging; PRES: Posterior reversible encephalopathy syndrome.

\section{Acknowledgements}

Not applicable.

\section{Authors' contributions}

$\mathrm{RH}$ interpreted the patient data and was a major contributor in writing the manuscript. SH performed the clinical examination. SM drafted the work and substantively revised it. All authors read and approved the final manuscript.

\section{Funding}

This research did not receive any specific grant from funding agencies in the public, commercial, or nonprofit sectors.

\section{Availability of data and materials}

The datasets used and/or analyzed during the current study are available from the corresponding author on reasonable request.

\section{Ethics approval and consent to participate}

Consent was obtained from the patient. This study adhered to the tenets of the Declaration of Helsinki.

\section{Consent for publication}

Written informed consent was obtained from the patient for publication of this case report and any accompanying images. A copy of the written consent is available for review by the Editor-in-Chief of this journal.

\section{Competing interests}

The authors declare that they have no competing interests.

\section{Author details}

${ }^{1}$ Department of Ophthalmology, Saitama Medical Center, Dokkyo Medical University, 2-1-50 Minamikoshigaya, Koshigaya, Saitama 343-8555, Japan.

${ }^{2}$ Lively Eye Clinic, 3-1-4 Asahicho, Soka, Saitama 340-0053, Japan.

Received: 26 September 2020 Accepted: 17 February 2021

Published online: 28 March 2021

\section{References}

1. Zambrano MD, Miller EC. Maternal stroke: an update. Curr Atheroscler Rep. 2019;21:33.

2. Feske SK, Singhal AB. Stroke in pregnancy: an update. Neurol Clin. 2019;37:131-48.

3. Call GK, Fleming MC, Sealfon S, Levine H, Kistler JP, Fisher CM. Reversible cerebral segmental vasoconstriction. Stroke. 1988;19:1159-70. 
4. Calabrese LH, Dodick DW, Schwedt TJ, Singhal AB. Narrative review: reversible cerebral vasoconstriction syndromes. Ann Intern Med. 2007;146:34-44.

5. Dodick DW. Thunderclap headache. J Neurol Neurosurg Psychiatry. 2002;72:6-11.

6. Singhal $A B$, Bernstein RA. Postpartum angiopathy and other cerebral vasoconstriction syndromes. Neurocrit Care. 2005;3:91-7.

7. Miller TR, Shivashankar R, Mossa-Basha M, Gandhi D. Reversible cerebral vasoconstriction syndrome, part 1: epidemiology, pathogenesis, and clinical course. AJNR Am J Neuroradiol. 2015;36:1392-9.

8. Singhal AB, Hajj-Ali RA, Topcuoglu MA, Fok J, Bena J, Yang D, et al. Reversible cerebral vasoconstriction syndromes: analysis of 139 cases. Arch Neurol. 2011;68:1005-12.

9. Morse PH, Morse PH. Elschnig's spots and hypertensive choroidopathy. Am J Ophthalmol. 1968;66:844-52.

10. Sattar A, Manousakis $G$, Jensen MB. Systematic review of reversible cerebral vasoconstriction syndrome. Expert Rev Cardiovasc Ther. 2010;8:1417-21.

11. Skeik N, Porten BR, Kadkhodayan Y, McDonald W, Lahham F. Postpartum reversible. Vasc Med. 2015;20:256-65.

12. Liu L, Tan Q, Huang R, Hu Z. Analysis of postpartum reversible cerebral vasoconstriction syndrome in China: a case report and literature review. Medicine. 2019;98:e17170

13. Ducros A, Boukobza M, Porcher R, Sarov M, Valade D, Bousser MG. The clinical and radiological spectrum of reversible cerebral vasoconstriction syndrome. A prospective series of 67 patients. Brain. 2007;130:3091-101.

14. Marder CP, Donohue MM, Weinstein JR, Fink KR. Multimodal imaging of reversible cerebral vasoconstriction syndrome: a series of 6 cases. AJNR Am J Neuroradiol. 2012;33:1403-10.

15. Ghia D, Cuganesan R, Cappelen-Smith C. Delayed angiographic changes in postpartum cerebral angiopathy. J Clin Neurosci. 2011;18:435-6.

16. Chen SP, Fuh JL, Wang SJ, Chang FC, Lirng JF, Fang YC, et al. Magnetic resonance angiography in reversible cerebral vasoconstriction syndromes. Ann Neurol. 2010;67:648-56.

17. Raven ML, Ringeise AL, McAllister AR, Knoch DW. Reversible cerebral vasoconstriction syndrome presenting with visual field defects. J NeuroOphthalmol. 2016;36:187-90.
18. Walia HS, Grumbine FL, Palejwala NV, Sawhney GK, Risner DS, Walia SS. A very rapid visual recovery of posterior reversible encephalopathy syndrome. J Clin Imaging Sci. 2011;1:36. https://doi.org/10.4103/2156-7514. 82341.

19. Sachdeva V, Garg R, Pathengay A, Chandrasekharan A, Kekunnaya R. Rapidly reversible visual loss in posterior reversible encephalopathy syndrome: an ophthalmologist's enigma. Oman J Ophthalmol. 2015;8:211-2.

20. Pehere NK, Dutton GN, Mankad K. Simultanagnosia as a cause of visual disturbance following posterior reversible encephalopathy syndrome (PRES): a case report. Indian J Ophthalmol. 2020;68:254-6.

21. Pilato F, Distefano M, Calandrelli R. Posterior reversible encephalopathy syndrome and reversible cerebral vasoconstriction syndrome: clinical and radiological considerations. Front Neurol. 2020;11:34. https://doi.org/10. 3389/fneur.2020.00034.

22. Pula JH, Eggenberger E. Posterior reversible encephalopathy syndrome. Curr Opin Ophthalmol. 2008;19:479-84.

23. Besirli CG, Sudhakar P, Wesolowski J, Trobe JD. Serous retinal detachment in hypertensive posterior reversible encephalopathy syndrome. AJNR Am J Neuroradiol. 2011;32:E203-5.

24. Inan S, Polat $\mathrm{O}$, Cetinkaya $\mathrm{E}$, Inan UU. Bilateral serous retinal detachment accompanied by a rare intraretinal fluid configuration in preeclampsia and PRES Syndrome. Rom J Ophthalmol. 2019;63:86-90.

25. Kishi S, Tso MO, Hayreh SS. Fundus lesions in malignant hypertension. I. A pathologic study of experimental hypertensive choroidopathy. Arch Ophthalmol. 1985;103:1189-97.

26. MacCumber MW, Flower RW, Langham ME. Ischemic hypertensive choroidopathy. Fluorescein angiography, indocyanine green videoangiography, and measurement of pulsatile blood flow. Arch Ophthalmol. 1993:111:704-5.

27. Fugate JE, Ameriso SF, Ortiz G, Schottlaender LV, Wijdicks EF, Flemming $\mathrm{KD}$, et al. Variable presentations of postpartum angiopathy. Stroke. 2012;43:670-6.

\section{Publisher's Note}

Springer Nature remains neutral with regard to jurisdictional claims in published maps and institutional affiliations.
Ready to submit your research? Choose BMC and benefit from:

- fast, convenient online submission

- thorough peer review by experienced researchers in your field

- rapid publication on acceptance

- support for research data, including large and complex data types

- gold Open Access which fosters wider collaboration and increased citations

- maximum visibility for your research: over $100 \mathrm{M}$ website views per year

At $\mathrm{BMC}$, research is always in progress.

Learn more biomedcentral.com/submissions 